\title{
Quality of Life of Patients on Maintenance Hemodialysis in Relation to Hemoglobin Level: A Multicenter Study from a Developing Country
}

\author{
Saha SK ${ }^{\mathrm{a}}$, Mansur MA ${ }^{\mathrm{b}}$, Chowdhury SR ${ }^{\mathrm{c}}$, Khan MAW ${ }^{\mathrm{d}}$, Iqbal M${ }^{\mathrm{e}}$, Chowdhury AA ${ }^{\mathrm{f}}$, Islam
} $\mathrm{RN}^{\mathrm{g}}$, Iqbal $\mathrm{S}^{\mathrm{h}}$

\begin{abstract}
Background: Anemia is common in patients with end stage renal disease (ESRD) and is associated with impaired quality of life (QOL). This study was done to evaluate the QOL of ESRD patients on maintenance hemodialysis (MHD) with different levels of hemoglobin $(\mathrm{Hb})$.

Methods: This cross-sectional study was conducted from January to December 2013 on 135 adult ESRD patients on MHD for $\geq 4$ months, at hemodialysis units of three tertiary care hospitals in Dhaka, Bangladesh. The patients were divided into three groups based on Hb levels (Group 1: $\mathrm{Hb}<9 \mathrm{gm} / \mathrm{dl}, n=45$, 33\%, Group 2: $\mathrm{Hb}$ 9-11 $\mathrm{gm} / \mathrm{dl}, n=53,39 \%$ and Group 3: $\mathrm{Hb}>11 \mathrm{gm} / \mathrm{dl}, n=37,28 \%$ ), provided their Hb levels were stable [ie. maintained with erythropoietin (EPO) or blood transfusion (BT) or both] over the previous four months. Subjects were interviewed by principal investigator using Kidney Disease Quality of Life Short Form Tool (KDQOL-SF-36 version 1.3) consisting of two domains with 38 questions with each item put on a 0 to 100 range, higher scores indicating better $Q O L$.

Results: The mean age was 50+12 years with male predominance (male:female $=1.5: 1$ ). Mean duration of hemodialysis was $12 \pm 11.8$ months (range 9 to 66 months). The average QOL score was 50. Comparison of QOL parameters between the three groups showed that symptoms/problems, effects of kidney disease, burden of kidney disease, cognitive function, quality of social interaction and sleep in the kidney disease specific domain as well as pain, emotional well-being, social function and energy/fatigue scale scores in the general health related domain were significantly higher in the group 2 and group 3 than group 1 patients (each with $p<0.001)$. Comparison of $Q O L$ parameters between anemia correction measures like EPO $(n=65,48.2 \%), B T$ $(n=42,31.1 \%)$ or both $(n=28,20.7 \%)$ showed that the group receiving EPO alone had better QOL [symptom/ problem ( $p$ 0.043), burden of kidney disease ( $p 0.000)$, sexual function ( $p 0.000)$, pain ( $p 0.008)$ and energy/ fatigue (p 0.036)] compared to those getting BT or even BT plus EPO.
\end{abstract}

Conclusion: Patients were found to have better QOL with higher Hb levels. The overall QOL can be improved significantly by correction of anemia.

Key words: Hemodialysis, hemoglobin, quality of life.

(BIRDEM Med J 2017; 7(3): 198-204)

\footnotetext{
Author Information

a. Dr. Shudhanshu Kumar Saha, Registrar, Nephrology, BIRDEM General Hospital.

b. Prof. Mohammad Abul Masur, Director, Transplant unit, BADAS.

c. Prof. Sohel Reza Choudhury, Department of Epidemiology \& Research, National Heart Foundation Hospital \& Research Institute.

d. Dr. Md. Abdul Wahab Khan, Consultant, Square Hospital Ltd.

e. Dr. Masud Iqbal, Associate Professor of Nephrology, SSMCH, Dhaka.

f. Prof. Ayub Ali Choudhury, Department of Nephrology, NIKDU.

g. Dr. Rafi Nazrul Islam, Assistant Registrar, Nephrology, BIRDEM General Hospital.

h. Prof. Sarwar Iqbal, Professor \& Head, Department of Nephrology, BIRDEM General Hospital.
}

Address of correspondence: Dr. Shudhanshu Kumar Saha, Registrar, Nephrology, BIRDEM General Hospital. Email: shudhanshukumarsaha@gmail.com

Received: October 22, 2016

Accepted: July 31, 2017 


\section{Introduction}

Patients with chronic kidney disease (CKD) are physically unwell, financially crippled and psychologically demoralized. ${ }^{1}$ Anemia is associated with impaired quality of life (QOL), reduced energy and higher morbidity and mortality. ${ }^{2}$ Physicians strive to improve the feeling of well-being of these patients, so that they may lead a meaningful life. Among the various ways to improve QOL, anemia correction was assumed to be an easy and effective method. Anemia correction in CKD patients is usually done by blood transfusion (BT), erythropoietin (EPO) or both. Health-related QOL refers to the measure of a patient's functioning, well-being and general health perception. ${ }^{3,4}$ Along with survival, patients' QOL is an important indicator of the effectiveness of the medical care they receive.

QOL depends on multiple factors. ${ }^{5}$ QOL is poor in patients on hemodialysis who are anemic. The actual target level of hemoglobin $(\mathrm{Hb})$ which provides optimum QOL scores in Bangladeshi hemodialysis patients is not known. This study aimed to assess and compare the QOL for patients with different $\mathrm{Hb}$ levels in order to find out the target level of $\mathrm{Hb}$ at which our hemodialysis patients would attain a better QOL. In addition, the association of each QOL item within the kidney disease specific domain and general health related domain with different clinical and laboratory parameters were evaluated.

\section{Methods}

This cross-sectional study was conducted from January to December 2013 at hemodialysis units at National Institute of Kidney Diseases and Urology (NIKDU), Bangladesh Institute of Research and Rehabilitation in Diabetes, Endocrine and Metabolic Disorders (BIRDEM) and Square Hospital, Dhaka, Bangladesh. One hundred and thirty five adult ( $>18$ years) end stage renal disease (ESRD) patients on regular maintenance haemodialysis (MHD) for $\geq 4$ months and with stable hemoglobin levels were selected by purposive sampling. Patients with malignancy, dementia and psychosis were excluded.

To label the patients as having stable hemoglobin levels, each patient's past four months' records of $\mathrm{Hb}$ levels were collected. If a patient's $\mathrm{Hb}$ level at the time of enrollment was the same as the mean of hemoglobin levels at the first three months, then that patient was labeled to have stable $\mathrm{Hb}$. The average units of BT per month as well as the average EPO used monthly (calculated over the first three of the last four months) were also recorded. The doses of EPO and BT per month were also considered to be constant if the average monthly dose administered over the first three months were the same as that instituted in the fourth or last month.

The patients were divided into three groups based on their average $\mathrm{Hb}$ level (mean of last three months tests) and QOL in each of these groups were compared. The groups were classified such as $<9 \mathrm{gm} / \mathrm{dl}$ (group 1), 9$11 \mathrm{gm} / \mathrm{dl}$ (group 2), and $>11 \mathrm{gm} / \mathrm{dl}$ (group 3). Subjects were interviewed once by the principal investigator using Kidney Disease Quality of Life Short Form Tool (KDQOL-SF-36 version 1.3) consisting of two domains with 38 questionnaires with higher scores indicating better QOL. ${ }^{6}$

In the kidney disease specific domain 11 scales (or areas) are used to assess the impact of renal impairment on the patient's life and in the general health domain there are 8 scales or areas of questioning. There are several questions or items within each of these nineteen areas. The Bangla version of the questionnaire was validated. Majority of the scales in the questionnaire showed good test-retest reliability. ${ }^{7}$ Patient specific information like age, gender and clinical data like hemodialysis duration, blood pressure and the use of BT or EPO were collected at the time of the face to face interview in a predesigned case record form.

The data were analyzed with the statistical software SPSS 11.5.0. Statistical significance was set at $\mathrm{p}<0.05$. Two tailed Student's t-test was used to compare quantitative difference between 2 groups. One-way analysis of variance (one way ANOVA) was used to compare quantitative difference between multiple groups. Association was seen by Pearson's correlation test.

\section{Results}

Total patients were 135 including 80 males. The mean duration of CKD in these patients was $4.9 \pm 5.1$ years. The patients were divided into three groups based on haemoglobin levels [(Group 1: $\mathrm{n}=45,33 \%)$; (Group 2: $\mathrm{n}=53,39 \%$ ) and (Group 3: $\mathrm{n}=37,28 \%)$ ].

Age, blood pressure and mean duration of dialysis were similar among the three groups as shown in Table I. 
Majority of the study subjects were anemic with $45 \%$ of the patients being BT dependent but with only $36 \%$ being on EPO while $19 \%$ received both. BT was taken by 27, 20 and 3 subjects in group 1, 2 and 3.

Comparison of different biochemical parameters like serum albumin, total protein, creatinine and $\mathrm{Kt} / \mathrm{V}$ (indicator of dialysis adequacy) were done between 3 $\mathrm{Hb}$ groups. It was found that there were no significant differences of all these parameters among the three groups (Table II).

Between the three groups transferrin saturation (TSAT) was also higher in group $3(>11 \mathrm{~g} / \mathrm{dl})$ than group $1(<9$ $\mathrm{g} / \mathrm{dl}),(p<0.001)$ (Table III).

Comparison of QOL score between the three groups showed majority of the scores for KDQOL-SF-36 were higher in group 3 than in group 1 (Tables IV and V).

Table I. Clinical parameters of different hemoglobin groups

\begin{tabular}{lccccc}
\hline Clinical parameters & $\begin{array}{c}<\text { gm/dl } \\
(\text { Mean } \pm \text { SD) }\end{array}$ & $\begin{array}{c}9-11 \text { gm/dl } \\
(\text { Mean } \pm \text { SD) }\end{array}$ & $\begin{array}{c}>11 \text { gm/dl } \\
(\text { Mean } \pm \text { SD) }\end{array}$ & $\begin{array}{c}\text { Total } \\
(\mathrm{n}=135)\end{array}$ & $\begin{array}{c}\text { P } \\
\text { value }\end{array}$ \\
\hline Age (years) & $48 \pm 12$ & $48 \pm 11$ & $52 \pm 12$ & $50 \pm 12$ & 0.160 \\
Systolic BP (mmHg) & $159 \pm 9$ & $160 \pm 10$ & $158 \pm 10$ & $160 \pm 10$ & 0.086 \\
Diastolic BP (mmHg) & $87 \pm 4$ & $90 \pm 6$ & $89 \pm 3$ & $89 \pm 5$ & 0.607 \\
Dialysis Duration (months) & $18.5 \pm 10$ & $22 \pm 14$ & $20 \pm 11$ & $12 \pm 11.8$ & 0.235 \\
Blood transfusion (unit per month) & $0.97 \pm 0.96$ & $1.0 \pm 0.97$ & $0.33 \pm 0.68$ & $0.84 \pm 0.94$ & 0.001 \\
Erythropoietin dose (unit/week) & - & - & & $2208 \pm 2135$ & - \\
\hline
\end{tabular}

Note $\mathrm{BT}=\mathrm{Blood}$ transfusion, $\mathrm{BP}=\mathrm{Blood}$ pressure

Table II. Biochemical parameters of the different hemoglobin groups

\begin{tabular}{lcccc}
\hline Biochemical parameter & $\begin{array}{c}<\mathrm{gm} / \mathrm{dl} \\
(\mathrm{n}=45)\end{array}$ & $\begin{array}{c}9-11 \mathrm{gm} / \mathrm{dl} \\
(\mathrm{n}=53)\end{array}$ & $\begin{array}{c}>11 \mathrm{gm} / \mathrm{dl} \\
(\mathrm{n}=37)\end{array}$ & $\begin{array}{c}\mathrm{P} \\
\text { value }\end{array}$ \\
\hline Serum albumin $(\mathrm{g} / \mathrm{dl})$ & $3.2 \pm 0.4$ & $3.2 \pm 0.4$ & $3.3 \pm 0.3$ & 0.545 \\
Serum total protein $(\mathrm{g} / \mathrm{dl})$ & $6.4 \pm 0.8$ & $6.4 \pm 1.1$ & $6.4 \pm 0.8$ & 0.962 \\
Serum creatinine(mg/dl) & $8.9 \pm 1.9$ & $9.3 \pm 3.2$ & $8.2 \pm 2.1$ & 0.114 \\
Kt/V & $0.99 \pm 0.2$ & $0.98 \pm 0.3$ & $1.1 \pm 0.28$ & 0.062 \\
\hline
\end{tabular}

Table III. Hematological parameter of different hemoglobin groups

\begin{tabular}{lccccc}
\hline Hematological parameter & $\begin{array}{c}<\mathrm{gm} / \mathrm{dl} \\
(\mathrm{n}=45)\end{array}$ & $\begin{array}{c}9-11 \mathrm{gm} / \mathrm{dl} \\
(\mathrm{n}=53)\end{array}$ & $\begin{array}{c}>11 \mathrm{gm} / \mathrm{dl} \\
(\mathrm{n}=37)\end{array}$ & $\begin{array}{c}\text { Total } \\
(\mathrm{n}=135)\end{array}$ & $\begin{array}{c}\mathrm{P} \\
\text { value }\end{array}$ \\
\hline Hemoglobin $(\mathrm{g} / \mathrm{dl})$ & $8.1 \pm .55$ & $9.6 \pm .4$ & $11.5 \pm .32$ & $9.6 \pm 1.3$ & 0.000 \\
Serum ferritin $(\mathrm{ng} / \mathrm{ml})$ & $511 \pm 322$ & $589 \pm 373$ & $576 \pm 379$ & $557 \pm 358$ & 0.536 \\
TSAT (transferrin saturation) $\%$ & $35 \pm 13$ & $37 \pm 14$ & $48 \pm 23$ & $39 \pm 19$ & 0.004 \\
\hline
\end{tabular}


Table IV. Quality of life parameter in Kidney disease specific domain between 3 hemoglobin groups

\begin{tabular}{lccccc}
\hline Items of quality of life & $\begin{array}{c}<9 \mathrm{gm} / \mathrm{dl} \\
(\mathrm{n}=45)\end{array}$ & $\begin{array}{c}9-11 \mathrm{gm} / \mathrm{dl} \\
(\mathrm{n}=53)\end{array}$ & $\begin{array}{c}>11 \mathrm{gm} / \mathrm{dl} \\
(\mathrm{n}=37)\end{array}$ & $\begin{array}{c}\text { Mean } \\
\text { Score } \pm \text { SD }\end{array}$ & $\begin{array}{c}\mathrm{P} \\
\text { value }\end{array}$ \\
\hline Symptom/problem & $62 \pm 8$ & $69 \pm 8$ & $72 \pm 8$ & $67 \pm 9$ & 0.000 \\
Effect of Kidney disease & $56 \pm 9$ & $58 \pm 8$ & $63 \pm 9$ & $59 \pm 9$ & 0.002 \\
Burden of Kidney disease & $5 \pm 9$ & $12 \pm 11$ & $21 \pm 11$ & $12 \pm 12$ & 0.000 \\
Cognitive function & $52 \pm 11$ & $65 \pm 15$ & $68 \pm 11$ & $62 \pm 14$ & 0.000 \\
Quality of social interaction & $70 \pm 13$ & $76 \pm 12$ & $84 \pm 11$ & $77 \pm 13$ & 0.000 \\
Sexual function & $23 \pm 37$ & $37 \pm 43$ & $53 \pm 44$ & $36 \pm 43$ & 0.012 \\
Sleep & $47 \pm 10$ & $53 \pm 9$ & $56 \pm 9$ & $52 \pm 9$ & 0.000 \\
Social support & $60 \pm 16$ & $62 \pm 18$ & $67 \pm 19$ & $62 \pm 18$ & 0.224
\end{tabular}

Table V. Quality of life parameter in General health related domain between 3 hemoglobin groups

\begin{tabular}{lccccc}
\hline Items of quality of life & $\begin{array}{c}<9 \mathrm{gm} / \mathrm{dl} \\
(\mathrm{n}=45)\end{array}$ & $\begin{array}{c}9-11 \mathrm{gm} / \mathrm{dl} \\
(\mathrm{n}=53)\end{array}$ & $\begin{array}{c}>11 \mathrm{gm} / \mathrm{dl} \\
(\mathrm{n}=37)\end{array}$ & $\begin{array}{c}\text { Mean } \\
\text { Score } \pm \text { SD }\end{array}$ & $\begin{array}{c}\mathrm{P} \\
\text { value }\end{array}$ \\
\hline Physical functioning & $43 \pm 29$ & $44 \pm 37$ & $45 \pm 31$ & $43 \pm 33$ & 0.957 \\
Role Physical & $18 \pm 39$ & $24 \pm 43$ & $12 \pm 33$ & $18 \pm 39$ & 0.402 \\
Pain & $33 \pm 16$ & $48 \pm 16$ & $65 \pm 20$ & $48 \pm 21$ & 0.000 \\
General health & $17 \pm 15$ & $36 \pm 15$ & $46 \pm 16$ & $32 \pm 19$ & 0.000 \\
Emotional well being & $67 \pm 20$ & $77 \pm 20$ & $91 \pm 21$ & $78 \pm 23$ & 0.000 \\
Role emotion & $15 \pm 7$ & $8 \pm 16$ & $12 \pm 16$ & $8 \pm 14$ & 0.002 \\
Social function & $34 \pm 11$ & $49 \pm 17$ & $61 \pm 19$ & $48 \pm 19$ & 0.000 \\
Energy / fatigue & $34 \pm 9$ & $43 \pm 13$ & $49 \pm 13$ & $42 \pm 13$ & 0.000 \\
Overall score & & & & $50 \pm 17$ & \\
\hline
\end{tabular}

\section{Comparison of quality of life parameters between the three hemoglobin groups}

QOL parameters were compared between group 2 and group 1 and showed that symptom/problem, burden of kidney disease, cognitive function, sleep, pain, general health, emotional well-being, social function and energy/ fatigue were higher in group 2 than group 1 . But the comparison in majority of scales between group 2 and group 3 were similar.

\section{Evaluation of Association}

Correlation between quality of life parameters in the three groups showed that all the kidney disease domain scale items score had a positive correlation with hemoglobin (Table VI).
Table VI. Correlation between quality of life parameter and 3 hemoglobin groups

\begin{tabular}{lcc} 
Quality of life parameters in & $\mathrm{R}^{2}$ & $\mathrm{P}$ value \\
\hline kidney specific domain & & \\
Symptom/problem & 0.166 & 0.000 \\
Effect of Kidney disease & 0.068 & 0.003 \\
Burden of Kidney disease & 0.219 & 0.000 \\
Cognitive function & 0.169 & 0.000 \\
Quality of social interaction & 0.197 & 0.000 \\
Sexual function & 0.69 & 0.003 \\
Sleep & 0.83 & 0.001 \\
Social support & 0.44 & 0.019 \\
\hline
\end{tabular}


Correlation between quality of life parameters in the three groups showed all the general health related domain scale item score had positive correlated with hemoglobin except physical functioning and role physical (Table VII).

Table VII. Correlation between quality of life parameter and 3 hemoglobin groups

\begin{tabular}{lcc}
\hline $\begin{array}{l}\text { Quality of life parameters } \\
\text { in general health domain }\end{array}$ & $\mathrm{R}^{2}$ & $\mathrm{P}$ value \\
\hline Physical functioning & 0.002 & 0.622 \\
Role Physical & 0.007 & 0.363 \\
Pain & 0.307 & 0.000 \\
General health & 0.301 & 0.000 \\
Emotional well being & 0.145 & 0.000 \\
Role emotion & 0.112 & 0.000 \\
Social function & 0.277 & 0.000 \\
Energy / fatigue & 0.168 & 0.000 \\
\hline
\end{tabular}

${ }^{2} 0.166, \mathrm{p}<.001$

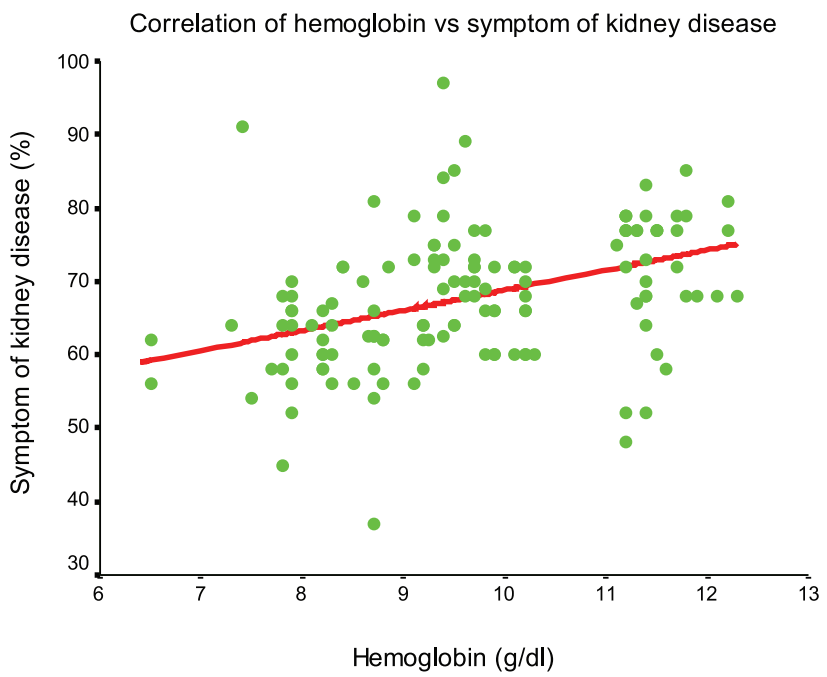

Figure 1. Higher hemoglobin is associated with higher symptom of kidney disease scale score.

\section{Comparison of quality of life parameters between the three therapeutic groups}

Comparison QOL parameters between anemia correction measures like EPO, BT and EPO plus BT showed significant differences in many areas (Table VIII).

Table VIII. Comparison of quality of life parameters between the three therapeutic groups

\begin{tabular}{|c|c|c|c|c|}
\hline Items & $\begin{array}{l}\text { Blood transfusion (BT) } \\
\qquad \mathrm{N}=42\end{array}$ & $\begin{array}{c}\mathrm{BT}+\mathrm{EPO} \\
\mathrm{N}=28\end{array}$ & $\begin{array}{c}\text { Erythropoietin } \\
\text { (EPO) } \mathrm{N}=65\end{array}$ & $\begin{array}{c}\mathrm{p} \\
\text { value }\end{array}$ \\
\hline \multicolumn{5}{|c|}{ QOL parameter for kidney disease specific domains } \\
\hline Symptom/problem & $66 \pm 9$ & $64 \pm 10$ & $69 \pm 8$ & 0.043 \\
\hline Effect of Kidney disease & $58 \pm 9$ & $59 \pm 8$ & $59 \pm 9$ & 0.779 \\
\hline Burden of Kidney disease & $7 \pm 10$ & $7 \pm 9$ & $17 \pm 11$ & 0.000 \\
\hline Cognitive function & $60 \pm 14$ & $59 \pm 17$ & $64 \pm 13$ & 0.140 \\
\hline Quality of social interaction & $74 \pm 13$ & $75 \pm 14$ & $78 \pm 12$ & 0.243 \\
\hline Sexual function & $14 \pm 29$ & $25 \pm 39$ & $55 \pm 43$ & 0.000 \\
\hline Sleep & $53 \pm 10$ & $48 \pm 9$ & $65 \pm 9$ & 0.076 \\
\hline Social support & $60 \pm 13$ & $57 \pm 20$ & $66 \pm 19$ & 0.043 \\
\hline \multicolumn{5}{|c|}{ QOL parameters for general health related domains } \\
\hline Physical functioning & $41 \pm 31$ & $40 \pm 32$ & $46 \pm 34$ & 0.585 \\
\hline Role Physical & $22 \pm 42$ & $12 \pm 33$ & $19 \pm 39$ & 0.577 \\
\hline Pain & $42 \pm 18$ & $48 \pm 21$ & $53 \pm 21$ & 0.008 \\
\hline General health & $42 \pm 30$ & $27 \pm 21$ & $65 \pm 37$ & 0.05 \\
\hline Emotional well being & $73 \pm 19$ & $75 \pm 25$ & $82 \pm 23$ & 0.076 \\
\hline Role emotion & $4 \pm 12$ & $7 \pm 16$ & $9 \pm 14$ & 0.274 \\
\hline Social function & $43 \pm 14$ & $41 \pm 19$ & $52 \pm 20$ & 0.007 \\
\hline Energy/ fatigue & $39 \pm 13$ & $40 \pm 11$ & $45 \pm 13$ & 0.036 \\
\hline
\end{tabular}




\section{Discussion}

In this study majority of our patients were above 50 years of age which is similar to MHD population in this subcontinent. ${ }^{8}$ The average age of MHD patients in Europe is 60, Japan 58 and in USA 60 years which is higher than current study. ${ }^{9}$ This may be due to better socioeconomic condition, increased life expectancy and longer survival on dialysis.

Mean $\mathrm{Hb}$ was $<10 \mathrm{gm} / \mathrm{dl}$ in the present study. Only $36 \%$ patients were on EPO alone and mean dose was $<3000$ unit/week. A multicenter study on patients with similar characteristics from India showed 50\% patients had similarly low $\mathrm{Hb}$ and their $84 \%$ patients were on EPO therapy getting mean dose around 4000 unit/week. ${ }^{10}$ The DOPPS study based on 12 countries from the developed part of world showed that their $94 \%$ patients were on EPO therapy having mean haemoglobib $12 \mathrm{gm} /$ $\mathrm{dl}$ with their EPO dosages ranging from 5,200 to 17,000 units/week. ${ }^{11}$ The low Hb of our study was most likely due to low EPO dose. The common causes of low $\mathrm{Hb}$ in dialysis patients is insufficient dialysis dose, reduced EPO dose and inflammation, uremic effect on bone marrow suppression and dialysis membrane defect. ${ }^{12-16}$

Kidney Disease Outcome Quality Initiative (KDOQI) Guidelines quoted studies when anemia correction was sub optimum the TSAT can be increased around 30$50 \%$ and ferritin around 1000 . This can reduce EPO dose by $25-40 \%$. In presenting study the TSAT and ferritin level was around the level of KDOQI recommendation but EPO dose was lower. So, an increase in intravenous iron can be an option where EPO dose cannot be increased.

The average QOL score in presenting study was 50 . Higher score indicates better QOL. The DOPPS study showed that QOL score was around 60 for Japan, USA and Europe. ${ }^{17}$ In this study the average $\mathrm{Hb}$ was around $10 \mathrm{~g} / \mathrm{dl}$. Another study found that normalization of $\mathrm{Hb}$ improved QOL score and decreased morbidity significantly. ${ }^{18}$

Comparison of QOL parameter between the three groups showed that symptom/problem, effect of kidney disease, burden of kidney disease, cognitive function, quality of social interaction, sexual function and sleep scale scores were higher in group 3 than group 1. A study in Thailand also compared QOL score between different Hb levels and showed higher $\mathrm{Hb}$ was associated with better QOL score in scales of general health, role emotion and social function which was similar to present study. ${ }^{19}$ Higher $\mathrm{Hb}$ level provides better QOL. Study on patients with three $\mathrm{Hb}$ cut offs similar to our study, showed that heighest score in QOL for physical and mental component was achieved when $\mathrm{Hb}$ was between 11-13g/ $\mathrm{dl}^{20}$

Comparison QOL parameters between anemia correction measures like EPO, BT or EPO plus BT showed EPO group showed higher QOL score in scales of symptom/problem, burden of kidney disease, sexual function, social support, pain, general health, social function and energy/fatigue. EPO therapies, apart from improving dialysis quality by correction of anemia improve QOL significantly. EPO increases oxygen consumption by the tissue and increases exercise capacity. Increase exercise capacity positively affects many QOL parameters that include subjective and objective indicator. Patient experiences relief from many debilitated symptoms of anemia, it also improves emotional and social well-being, appetite and sleep pattern. ${ }^{21}$

Intervention to improve mobility and strength can improve physical functioning which is a common disability in ESRD population..$^{22}$ Correction of anemia, even suboptimum by the use of EPO improved physical functioning and energy. ${ }^{23}$ Sexual dysfunctions exist at least in half of the ESRD patient which is often under recognized. ${ }^{24}$ Also sleep is a problem may affect $80 \%$ of ESRD patients. ${ }^{25}$ Significant improvement in sexual function and better sleep in EPO group is evident in presenting study.

\section{Conclusion}

Patients with higher hemoglobin have better quality of life and anemia correction is indeed one of the ways to improve QOL. EPO alone improved QOL than BT or even BT plus EPO group.

\section{Limitations}

This is a small scale study. A study with greater number of participants would have provided better results.

\section{Conflict of Interest: None}




\section{References}

1. El-Shahed AM, Shadia A. Sharf SA, Hanan A. El Sebaee HA, Roshdy MM. Hemoglobin Level Associated Co-Morbidities and Quality of Life among Patients Undergoing Hemodialysis at One of the University Hospitals in Cairo Governorate. World Applied Sciences Journal 2013; 23: 29-36.

2. Portoles JM, de Francisco ALM. Maintenance of target hemoglobin level in stable hemodialysis patients constitutes a theoretical task a historical prospective study. Kidney International 2008; 74: 82-87.

3. Germin-Petrovi D, Devcic IM, Lesac A, Mandic M, Soldatic M, Vezmar D, et al. Health-related Quality of Life in the Patients on Maintenance Hemodialysis: The Analysis of Demographic and Clinical Factors. Coll Antropol 2011; 35 : 687-93.

4. El hamed Ali HMA, Elsebai NAM, Ramadan FAF, Salam WIS, Abdelhady TMA. Impact of Teaching Guidelines on Quality of Life for Hemodialysis Patients. Nature and Science 2011; 9:214-22.

5. Kusleikaite N, Bumblyte IA, Kuzminskis V, Rûta V. The association between health-related quality of life and mortality among hemodialysis patients. Medicina (Kaunas) 2010; 46: 531-37.

6. Carmichael P, Popoola J, John I, Stevens PE, Carmichael AR. Assessment of quality of life in a single centre dialysis population using the KDQOL-SF questionnaire. Qual Life Res 2000; 9:195-205.

7. Pakpour AH, Jad MY, Molsted S, Harrison AP, Hasemi F, Saffari M. Translation, cultural adaptation assessment, and both validity and reliability testing of the Kidney Disease Quality of Life - Short Form version 1.3 for use with Iranian patientsn. Nephrology 2011; 16:106-12.

8. Sultania P, Acharya PS, Sharma SK. Adequacy of hemodialysis in Nepalese patients undergoing maintenance hemodialysis. J Nepal Med Assoc 2009; 48:10-13.

9. Goodkin DA, Young EW, Kurokawa K, Prütz KG, Levin NW. Mortality among hemodialysis patients in Europe, Japan, and the United States: case-mix affects. Am J Kidney Dis 2004; 44:16-21.

10. Gouswami S, Bhowmick S, Majumdar A, Sikdar S, Sarker CN. Appropiateness and efficacy of the use of erythropoietin in haemodialysis patient. Indian population Medical Science 2014; 7: 15-22.

11. Pisoni RL, Bragg-Gresham JL, Young EW, Akizawa T, Asano $\mathrm{Y}$, Locatelli F, et al. Anemia management and outcomes from 12 countries in the Dialysis Outcomes and Practice Patterns Study (DOPPS). Am J Kidney Dis 2004; 44:94-111.

12. Panagoutsos SA, Yannatos EV, Passadakis PS, Thodis ED, Galtsidopoulos OG, Vargemezis VA. Effect of haemodialysis dose on anaemia, hypertension and nutrition. Ren Fail 2002; 2: $615-21$.

13. Kalantar-Zadeh K, Block G, McAllister CJ, Humphreys MH, Kopple JD. Appetite and inflammation, nutrition, anemia, and clinical outcome in hemodialysis patients. Am J Clin Nutr 2004; 80:299-307.

14. Locatelli F, Pisoni RL. Anaemia in haemodialysis patients of five European countries: association with morbidity and mortality in the Dialysis Outcomes and Practice Patterns Study (DOPPS). Nephrol Dial Transplant 2004; 19: 121-32.

15. Locatelli F, Del Vecchio L. Dialysis adequacy and response to erythropoietic agents: what is the evidence base? Nephrol Dial Transplant 2003; 18:29-35.

16. Ayli D, Ayli M, Azak A, Yüksel C, Kosmaz GP, Atilgan G, et all. The effect of high-flux hemodialysis on renal anemia. J Nephrol 2004; 17:701-6.

17. Fukuhara S, Lopes AA, Bragg-Gresham JL, Kurokawa K, Mapes DL, Akizawa T, et all. Health-related quality of life among dialysis patients on three continents: the Dialysis Outcomes and Practice Patterns Study. Kidney Int 2003; 64:1903-10.

18. Moreno F, Sanz-Guajardo D, López-Gómez JM, Jofre R, Valderrábano F. Increasing the hematocrit has a beneficial effect on quality of life and is safe in selected hemodialysis patients. Spanish Cooperative Renal Patients Quality of Life Study Group of the Spanish Society of Nephrology. J Am Soc Nephrol 2000; 11:335.

19. Thaweethamcharoen T, Sakulbumrungsil R, Vasuvattakul S, Nopmaneejumruslers C. Quality of Life and Hemoglobin Levels of Hemodialysis Patient at Siriraj Hospital. Siriraj Med J 2011; 63: 12-16.

20. Veerappan RM, Ilayabharthi AV. Predictors of quality of life of hemodialysis patients in India. Indian J Nephrol 2012; 22 : $18-25$.

21. Levin NW. Quality of life and hematocrit level. Am J Kidney Dis 1992; 20:16-20.

22. Johansen KL. Exercise in the end-stage renal disease population. J Am Soc Nephrol 2007; 18: 1845-54.

23. Leaf DE, Goldfarb DS. Interpretation and review of healthrelated quality of life data in $\mathrm{CKD}$ patients receiving treatment for anemia. Kidney Int 2009; 75: 15-24.

24. Finkelstein FO, Shirani S, Wuerth D, Finkelstein SH. Therapy Insight: Sexual dysfunction in patients with chronic kidney disease. Nat Clin Pract Nephrol 2007; 3: 200-207.

25. Gusbeth-Tatomir P, Boisteanu D, Seica A, Buga C, Covic A. Sleep disorders: A systematic review of an emerging major clinical issue in renal patients. Int Urol Nephrol 2007; 39: 1217-26. 